\title{
Comparison of local anaesthetic techniques in the reduction of Colles' fracture
}

\author{
J. WARDROPE, M. FLOWERS AND D. H. WILSON \\ Department of Accident and Emergency, General Infirmary, Leeds, England
}

\section{SUMMARY}

A trial comparing the use of Bier's block and the direct infiltration of the fracture site with local anaesthetic was carried out to assess their effectiveness in the reduction of Colles' fracture. This showed Bier's block to be superior in terms of patient acceptability and in ease of reduction. The results of the reduction were also significantly better using the Bier's block, as judged by the measurement of the residual displacement on the X-ray.

\section{INTRODUCTION}

Bier's block is increasingly used in the reduction of wrist fractures. However, there have been reports of side-effects following the use of this procedure and a few deaths have occurred. Thus it has been recommended that two doctors should be present during a Bier's block (Casualty Surgeons Association, 1983).

The injection of local anaesthetic into the site of the fracture has been suggested to be an acceptable alternative for the manipulation of wrist fractures (Dinley \& Michelinakis, 1973). This technique has also been used in our department. Since direct infiltration is not likely to cause systemic side-effects it might be preferable to use this technique if it could be shown to be as effective as Bier's block.

The trial was undertaken to compare these two methods and to assess whether there was any difference in the results of the routine management of Colles' fracture.

Correspondence: $\mathrm{Mr}$ F. Wardrope, Department of Accident and Emergency, Royal Hallamshire Hospital, Sheffield S10 2fD, England 


\section{METHODS}

Patients with Colles' fractures requiring manipulation were asked to take part in thê trial. The patients were over 45 years of age, had had no previous wrist fracture on tho injured side and had none of the contra-indications to Bier's block or to local anaesthesia.

The patients were examined, weighed and their blood pressure measured and tru lateral and antero-posterior X-rays taken.

The following techniques of local anaesthesia were used on alternate days:

Bier's block. $0.5 \%$ plain prilocaine (Citanest) was used in a dose of $0.6 \mathrm{ml} / \mathrm{kg}$. 'butterfly' was inserted into a vein on the dorsum of the injured hand. Another 'butterfly? was placed in a vein of the normal hand to give quick access to the circulation should ang systemic reactions occur. The injured limb was then elevated for a few minutes and well-padded single cuff was placed around the arm. The cuff was then inflated $100 \mathrm{~mm} \mathrm{Hg}$ above the systolic pressure and the injection of $0.5 \%$ plain prilocaine given slowly over about one minute. After 5 minutes the manipulation was carried out.

Direct infiltration. $1 \%$ plain lignocaine was used in a dose of $0.2 \mathrm{ml} / \mathrm{kg}$. The area was palpated to establish the level of the fracture.

The skin over the dorsum of the fracture site and the ulnar side of the wrist was thoroughly cleaned with an iodine solution. Observing aseptic precautions a 23-gauge needle was inserted into the fracture site through the dorsum of the wrist (Fig. 1). Enfory

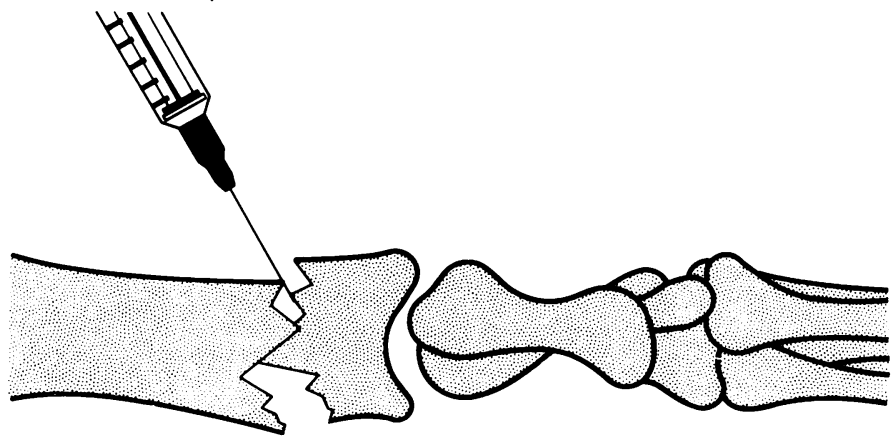

Fig. 1 A lateral view of Colles' fracture illustrating the site of injection for the local anaesthetic agent.

into the fracture haematoma was indicated by the reflux of blood in the syringe barreh About four-fifths of the total dose was given in this site; the rest was injected into the area of the ulnar styloid. After a period of 5 minutes the manipulation was performedis

Following the manipulation a padded plaster of Paris backslab was applied and chect $\mathrm{X}$-rays taken. If the reduction was thought to be inadequate then a further attempt was made during the same anaesthetic.

The doctor performing the manipulation completed a questionnaire recording the patient's details, the interval between injury and reduction, the presence of any pre 
manipulation complications, the number of attempts needed to achieve satisfactory reduction and the occurrence of any complications.

The nurse attending then helped the patient to complete a questionnaire about the anaesthetic (Fig. 2). As well as the direct question about the severity of the pain, a Visual Analogue Scale was included since this is thought to be a more reliable indicator of pain (Revill et al., 1976).

Name of patient

$A / E N o$.

The following questions are to be asked by the nurse attending.

(1) How painful was the procedure? (Ring appropriate word)

Unbearable/very painful/painful/uncomfortable/just noticeable/painless

(2) What was the worst part of the procedure? (Ring appropriate word)

The needles/the injection/the pulling/the cuff/other

(3) Would you rather have been given a general anaesthetic (put to sleep)?

\section{Yes/no}

(4) Look at the line below. One end represents no pain and the other represents the worst pain that you can imagine. Where would you gauge the pain of the procedure? For example, if you thought the procedure was very painful but not the worst pain you have had then the line would be marked thus:
Example
No pain
I---
Mark your pain No pain
-I Worst

Fig. 2 Patient questionnaire.

(a)

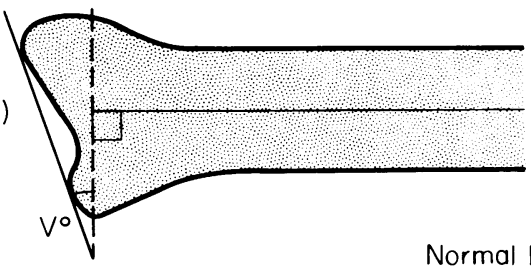

Normal $10-15^{\circ}$

(b)

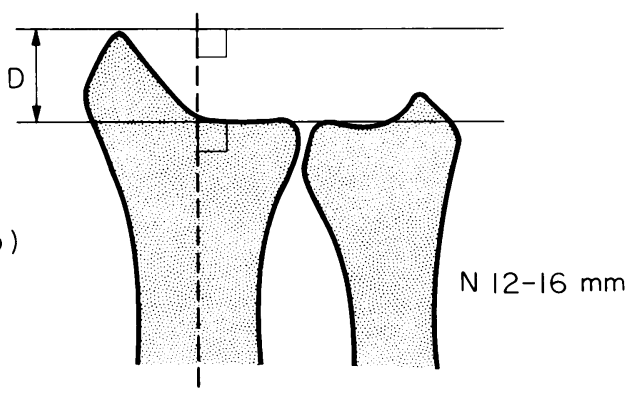

(c)

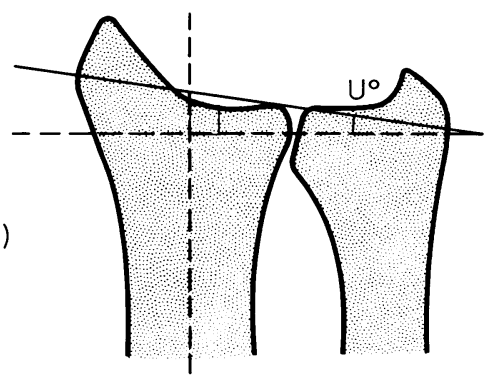

Fig. 3 (a) Volar angulation, lateral X-ray; (b) distance from radial styloid to plain of ulnar articular surface, antero-posterior X-ray; (c) ulnar angulation of articular surface of radius. 
The patients were followed up in the fracture clinic.

The X-rays were analysed by measuring the volar angulation on the lateral film, the ulnar inclination of the articular surface of the radius on the antero-posterior view and the distance between the articular surface of the ulna and the tip of the radial styloid (Fig. 3) (Friberg \& Lundstrom, 1976).

The notes of the patients were reviewed following discharge from the fracture clin to record complications or if re-reduction had been necessary.

The data were analysed using Student's $t$ test and the chi-squared test.

\section{RESULTS}

The two groups were comparable in age and initial degree of displacement of the fracture (Table 1).

Table 1 Mean values for the patients at presentation (standard deviation)

\begin{tabular}{|c|c|c|c|c|c|}
\hline & Local & Bier's & Stat. & Signif. & \\
\hline Age (years) & $\begin{array}{l}65 \cdot 0 \\
(9 \cdot 2)\end{array}$ & $\begin{array}{c}64 \cdot 5 \\
(10 \cdot 0)\end{array}$ & $t=0 \cdot 18$ & $p>0.5$ & \\
\hline $\begin{array}{l}\text { Initial volar } \\
\text { angulation (degrees) }\end{array}$ & $\begin{array}{c}-25 \cdot 4 \\
(11 \cdot 0)\end{array}$ & $\begin{array}{l}-23.6 \\
(9.5)\end{array}$ & $t=0 \cdot 70$ & $\mathrm{p}>0.1$ & \\
\hline $\begin{array}{l}\text { Initial ulnar } \\
\text { angulation (degrees) }\end{array}$ & $\begin{array}{l}3.4 \\
(6.9)\end{array}$ & $\begin{array}{c}6 \cdot 1 \\
(8 \cdot 0)\end{array}$ & $t=1.53$ & $0.5>p>0.1$ & \\
\hline $\begin{array}{l}\text { Initial distance } \\
(\mathrm{mm})\end{array}$ & $\begin{array}{l}5 \cdot 6 \\
(3 \cdot 2)\end{array}$ & $\begin{array}{l}6 \cdot 1 \\
(3 \cdot 8)\end{array}$ & $t=0.58$ & $p>0.5$ & \\
\hline
\end{tabular}

The first attempt at reduction was not satisfactory in more cases in the local infiltration group than in the Bier's block group (Table 2). Analysis of the final check X rays showed that in the Bier's block group a better reduction had been achieved. There were significant differences in the ulnar angulation and the distance between the articular surface of the ulna and the radial styloid (Table 3).

The patients appeared to experience less pain with the Bier's block as shown by the responses to both pain questions in the questionnaire (Tables 4 and 5). Five patients il the local infiltration group and four in the Bier's block group said that they would have preferred a general anaesthetic.

Table 2 Numbers of patients requiring more than one manipulation at first anaesthetic

\begin{tabular}{|c|c|c|c|}
\hline & Local & Bier's & \\
\hline$>1$ manipulation & 12 & 6 & $x^{2}=4.32 p<0.05$ \\
\hline 1 manipulation & 24 & 39 & \\
\hline
\end{tabular}


Table 3 Post reduction radiographic measurements. Mean values (standard deviation)

\begin{tabular}{lccl}
\hline & Local & Bier's & \\
\hline & 2.6 & 4.5 & $t=0.980 .5>\mathrm{p}>0.1$ \\
Volar angulation & $(8.6)$ & $(8.1)$ & \\
(degrees) & 9.6 & 13.6 & $t=2.8 \mathrm{p}>0.01$ \\
Ulnar angulation & $(5.2)$ & $(6.6)$ & \\
(degrees) & 9.1 & 10.9 & $t=2.74 \mathrm{p}>0.01$ \\
Distance & $(3.2)$ & $(2.3)$ & \\
$(\mathrm{mm})$ & &
\end{tabular}

Table 4 Numbers of patients responding

\begin{tabular}{lrrl} 
& $\begin{array}{c}\text { Local } \\
(n=37)\end{array}$ & $\begin{array}{c}\text { Bier's } \\
(n=42)\end{array}$ & \\
& & & \\
Painless & 1 & 11 & \\
Just noticed & 8 & 7 & $\mathrm{x}^{2}=9 \cdot 82$ \\
Uncomfortable & 12 & 13 & $0.05>\mathrm{p}>0.02$ \\
Painful & 9 & 8 & \\
Very painful & 7 & 3 & \\
\hline
\end{tabular}

Table 5 Pain scale, numbers of patients marking the scale at less than and more than $2 \mathrm{~cm}$ from the 'no pain' end

\begin{tabular}{lrrl}
\hline \multicolumn{3}{c}{ Local } & \multicolumn{3}{c}{ Bier's } \\
\hline$<2 \mathrm{~cm}$ & 8 & 21 & $\mathrm{x}^{2}=6.8$ \\
$>2 \mathrm{~cm}$ & 29 & 21 & $\mathrm{p}<0.05$ \\
\hline
\end{tabular}

Three patients in the direct infiltration group required to have an early re-reduction of the fracture. None in the Bier's group required early re-reduction. There were no problems due to infection in either group. There were equal numbers of problems with swelling and neurological symptoms in the two groups and there was no significant difference in the time to discharge from the fracture clinic.

\section{DISCUSSION}

We have found Bier's block to be a safe and effective method of anaesthesia for the reduction of Colles' fracture. Our junior staff are given training in the technique early in their stay in the department and are aware of the possible complications of the technique and the measures to take should these occur. We have tried to keep the procedure as simple as possible by using a single cuff and a bicycle pump to inflate the cuff. We have always used prilocaine in the past and there have been no major complications due to Bier's block. 
The direct infiltration technique is quicker to perform and there is less chance of anm intravenous bolus of local anaesthetic agent being given by mistake. However, direc infiltration would appear to give less satisfactory results than Bier's block in the hands of our junior staff.

We conclude that Bier's block is a better method of local anaesthesia in this situation

\section{ACKNOWLEDGEMENTS}

We wish to thank the nursing staff for their help in completing the questionnaires, $\mathrm{Mr}_{\mathrm{r}}$ Silk, Mr Longton, $\mathrm{Mr}$ Nelson and $\mathrm{Mr}$ Abberton for allowing access to the follow-up. notes of the patients, Miss Durbin of the Medical Illustration Department for $\vec{\omega}$ providing Figures 1 and 3 and the Department of Anatomy, Leeds Medical School for computing facilities.

\section{REFERENCES}

Casualty Surgeons Association (1983) Bier's Blocks (Intravenous Regional Anaesthesia). Code of Practice. Dinley R. J. \& Michelinakis E. (1973) Local anaesthesia in the reduction of Colles fracture. Injury 4, 345-6. $\vec{\bullet}$ Friberg S. \& Lundstrom B. (1976) Radiographic measurements of the radio-ulnar joint in normal adults. Acta $a_{G}^{\infty}$ Radiologica (Diagnosis) 17, 249-56.

Revill S. I., Robinson J. O., Rosen M. \& Hogg M. I. J. (1976) The reliability of a linear analogue in evaluatikg일 pain. Anaesthesia 31, 1191-8.

Received 9 October 1984; accepted for publication 19 November 1984 